\title{
Two Novel Semisynthetic Lipoglycopeptides Active against Staphylococcus aureus Biofilms and Cells in Late Stationary Growth Phase
}

\author{
Vladimir Vimberg ${ }^{1, *}$, Leona Zieglerova ${ }^{1}$, Aninda Mazumdar ${ }^{1}\left(\mathbb{D}\right.$, Zsolt Szúcs ${ }^{2}$, Aniko Borbás ${ }^{2}$ (D), Pál Herczegh ${ }^{2}$ \\ and Gabriela Balikova Novotna ${ }^{1}$
}

1 Institute of Microbiology, Czech Academy of Sciences, Průmyslova 595, 25250 Vestec, Czech Republic; zieglerova.leona@seznam.cz (L.Z.); anindamazumdar@gmail.com (A.M.); gnovotna@biomed.cas.cz (G.B.N.)

2 Department of Pharmaceutical Chemistry, University of Debrecen, Egyetem Tér 1, H-4032 Debrecen, Hungary; szucs.zsolt@pharm.unideb.hu (Z.S.); borbas.aniko@pharm.unideb.hu (A.B.); herczeghp@gmail.com (P.H.)

* Correspondence: vladimir.vimberg@gmail.com

check for updates

Citation: Vimberg, V.; Zieglerova, L.; Mazumdar, A.; Szúcs, Z.; Borbás, A.; Herczegh, P.; Novotna, G.B. Two

Novel Semisynthetic

Lipoglycopeptides Active against Staphylococcus aureus Biofilms and Cells in Late Stationary Growth Phase. Pharmaceuticals 2021, 14, 1182. https://doi.org/10.3390/ph14111182

Academic Editor: Gill Diamond

Received: 8 October 2021

Accepted: 17 November 2021

Published: 19 November 2021

Publisher's Note: MDPI stays neutral with regard to jurisdictional claims in published maps and institutional affiliations.

\begin{abstract}
The increase in antibiotic resistance among Gram-positive bacteria underscores the urgent need to develop new antibiotics. New antibiotics should target actively growing susceptible bacteria that are resistant to clinically accepted antibiotics including bacteria that are not growing or are protected in a biofilm environment. In this paper, we compare the in vitro activities of two new semisynthetic glycopeptide antibiotics, MA79 and ERJ390, with two clinically used glycopeptide antibiotics-vancomycin and teicoplanin. The new antibiotics effectively killed not only exponentially growing cells of Staphylococcus aureus, but also cells in the stationary growth phase and biofilm.
\end{abstract}

Keywords: antibiotic resistance; glycopeptide antibiotics; Staphylococcus aureus; teicoplanin pseudoaglycon

\section{Introduction}

For many years, the glycopeptide antibiotics vancomycin (VAN) and teicoplanin (TEI) (Figure 1) were the only glycopeptide antibiotics used clinically to treat severe infections caused by methicillin-resistant Staphylococcus aureus (MRSA), currently recognized by the World Health Organization as one of the greatest threats to world health [1]. These antibiotics bind to the D-alanyl-D-alanine (D-Ala-D-Ala) terminus of the cell wall peptidoglycan precursor of the actively dividing bacterial cell. This interaction inhibits peptidoglycan polymerization, resulting in the disruption of cell wall synthesis. While vancomycin binds to the nascent peptidoglycan chain in a dimerized form, teicoplanin has been proposed to bind to the cell membrane lipid II substrate via its lipophilic acyl side chain, bringing the antibiotic in close proximity to the nascent peptidoglycan [2-4]. Vancomycin and teicoplanin are not active against non-dividing cells. Nonetheless, the transition of S. aureus from active growth to the non-dividing state induces the expression of a variety of virulence factors that facilitate bacterial invasion, local spread of infection [5], and biofilm formation; therefore, it is important to develop antibiotics that can act on non-dividing S. aureus cells.

Recently, we introduced a new group of glycopeptide derivatives in which the primary amino function of the teicoplanin pseudoaglycone was replaced [6-8]. Figure 1 shows maleimido teicoplanin pseudoaglycone with two propylthiol groups (MA79) and teicoplanin pseudoaglycone derivative with a lipophilic n-decyl chain (ERJ390), both of which exhibited in vitro activity against clinical isolates of S. aureus, coagulase-negative staphylococci (CoNS): Staphylococcus epidermidis and Staphylococcus haemolyticus (including biofilm-producing strains) [9].

The new glycopeptide antibiotics MA79 and ERJ390 were effective against vancomycinintermediate $S$. aureus (VISA) and against CoNS resistant to teicoplanin. They also showed good efficacy against vanA- and vanB-type vancomycin-resistant enterococci (VRE). The 
vanA- and vanB-type resistance is mediated by the conversion of D-Ala-D-Ala-containing peptidoglycan precursors to D-alanine-D-lactate, which reduces the affinity of vancomycin and teicoplanin [4]. The preservation of MA79 and ERJ390 activity against VRE strains suggests that the binding of MA79 and ERJ390 to D-Ala-D-Ala is not the main antibiotic target [9]. The comparison of the potential of MA79 and ERJ390 to compete with fluorescently labeled vancomycin and teicoplanin bound to the cell wall of the S. aureus ATCC29213 strain confirmed that MA79 and ERJ390 are bound to the bacterial cell wall not only via D-Ala-D-Ala residues of the nascent peptidoglycan, but that the lipophilic substituents of MA79 and ERJ390 also enhanced the interaction of the antibiotics with the cell [9].

VAN

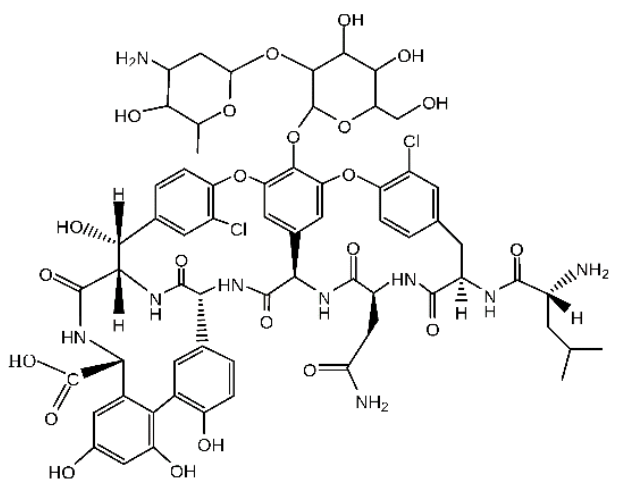

TEI

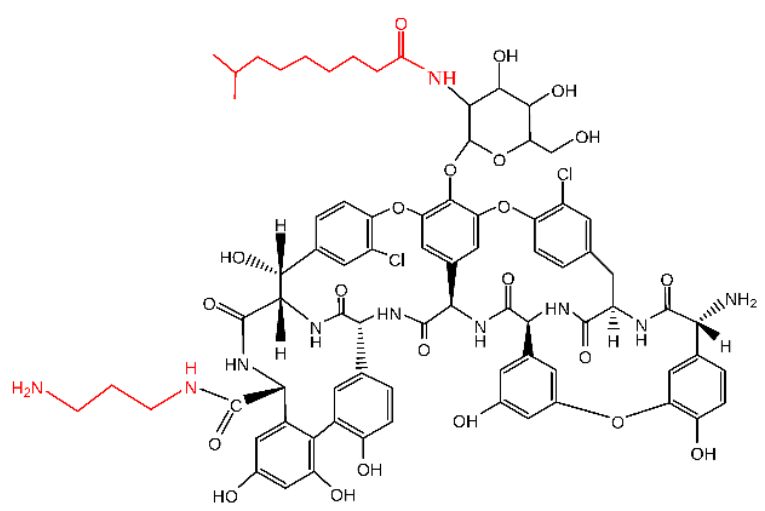

MA79

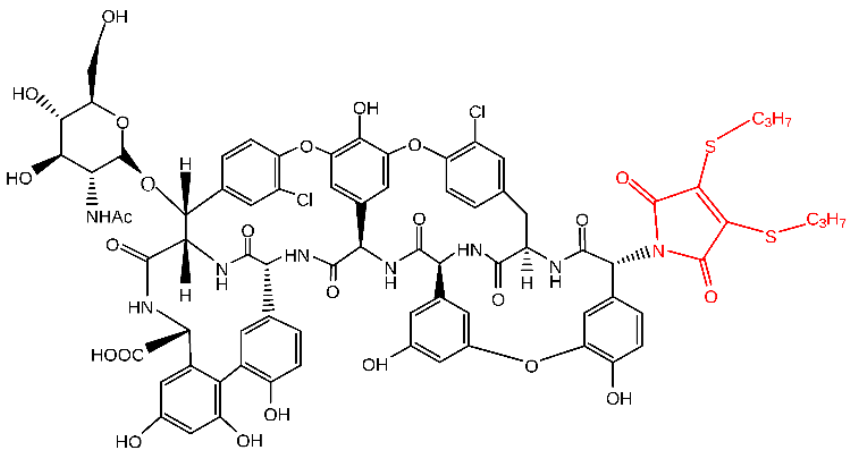

ERJ390

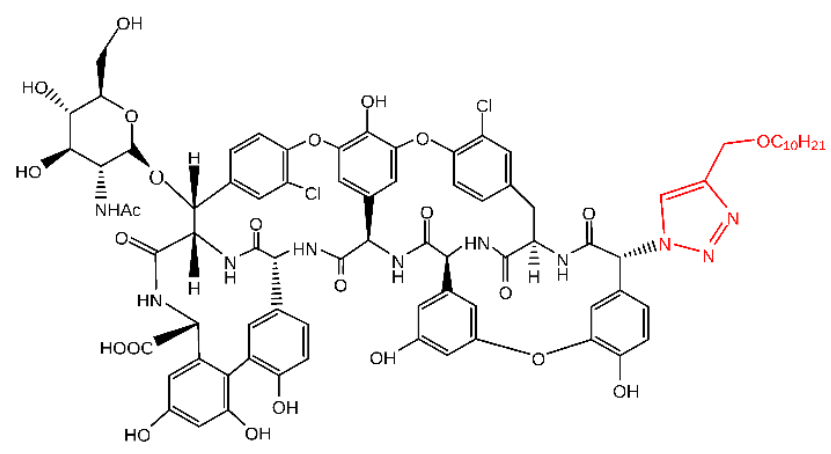

Figure 1. Chemical structures of the antibiotics: vancomycin (VAN), teicoplanin (TEI), MA79, and ERJ390. Lipophilic moieties are highlighted in red.

We hypothesized that the enhanced interaction of MA79 and ERJ390 with the bacterial cell wall could kill S. aureus cells even in the non-dividing state. Therefore, we compared the bacteriolytic properties of the antibiotics against $S$. aureus at different growth stages as well as in biofilm.

\section{Results}

2.1. MA79 and ERJ390 Are Bactericidal against Exponential and Stationary-Phase S. aureus

To investigate the bacteriolytic activity of the new lipoglycopeptide antibiotics MA79 and ERJ390, S. aureus strain 8325 was grown to the exponential or late stationary growth phase (see Figure S1) and then treated with either MA79, ERJ390, VAN, or TEI.

Firstly, we tested the ability of the antibiotics at concentrations 5, 10, and 50 times higher than the MIC (see Section 4) to kill S. aureus 8325 cells in one hour of incubation (see Figure 2a). MA79 and ERJ390 killed exponentially growing cells at concentrations 
that exceeded the MIC of the antibiotics by 5 -fold (see Figure 2a). However, concentrations of VAN and TEI 10-fold higher than the corresponding MICs were required to kill exponentially growing cells in one hour (see Figure 2a).

Secondly, we tested the ability of the antibiotics at concentrations five times higher than the MICs to kill S. aureus 8325 cells after 1, 4, and $24 \mathrm{~h}$ of incubation with the antibiotics. MA79 and ERJ390 at concentrations five times higher than their MICs killed the cells in the exponential phase after one hour, while VAN and TEI could not completely sterilize the growth medium even after $24 \mathrm{~h}$ (see Figure $2 \mathrm{~b}$ ).

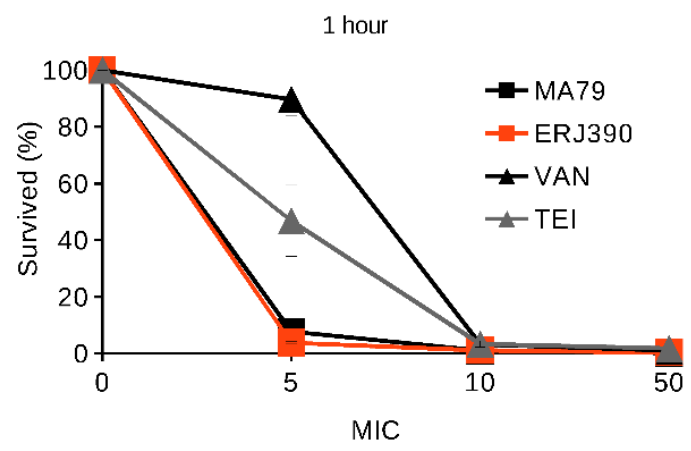

(a)

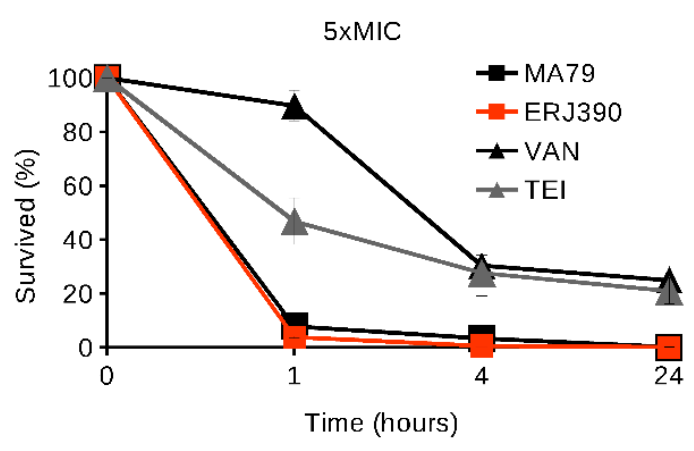

(b)

Figure 2. Killing of S. aureus 8325 cells in exponential phase by antibiotics vancomycin (VAN), teicoplanin (TEI), MA79, and ERJ390 at one hour after treatment of the bacteria with the antibiotics at various concentrations exceeding the MIC (a); or at time points after treatment of the bacteria with the antibiotics at a concentration exceeding the MIC 5-fold (b).

MA79 and ERJ390 were also more active than VAN and TEI in killing cells of S. aureus 8325 in the late stationary phase (see Figure 3). ERJ390 and MA79 killed approximately $80 \%$ and $40 \%$ of cells, respectively, within one hour at concentrations 50 -fold higher than the MIC (see Figure 3a), whereas VAN and TEI were nearly inactive. After $24 \mathrm{~h}$, both MA79 and ERJ390 at concentrations 50-fold higher than the MIC had completely sterilized the growth medium (see Figure $3 b$ ).

Antibiotics MA79 and ERJ390 were also bactericidal against the exponential and stationary phase cells of vancomycin-susceptible $S$. aureus Newman and vancomycinintermediate S. aureus Mu50 strains (see Figure 4). ERJ390 was the most active compound against all $S$. aureus strains tested.

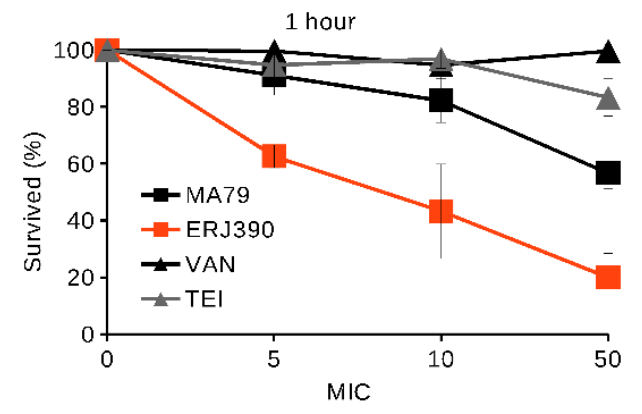

(a)

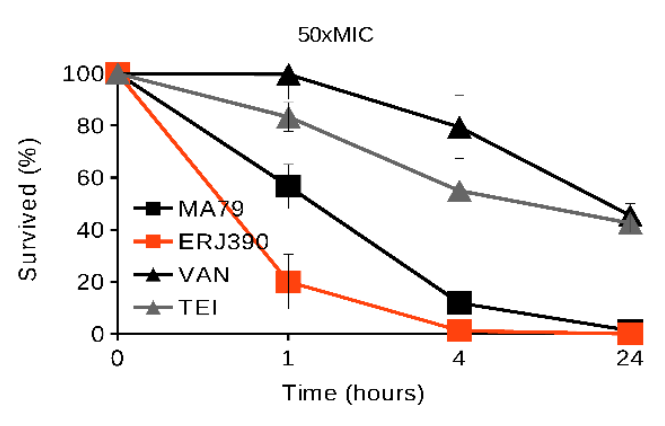

(b)

Figure 3. Killing of S. aureus 8325 cells in stationary phase by antibiotics vancomycin (VAN), teicoplanin (TEI), MA79, and ERJ390 at one hour after treatment of the bacteria with the antibiotics at various concentrations exceeding the MIC (a) and at time points after treatment of the bacteria with the antibiotics at a concentration exceeding the MIC 50-fold (b). 


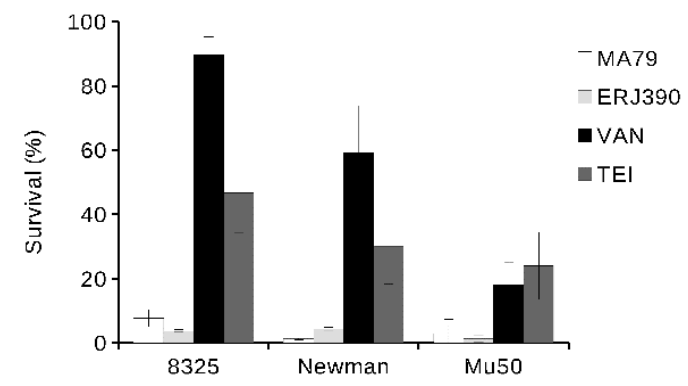

(a)

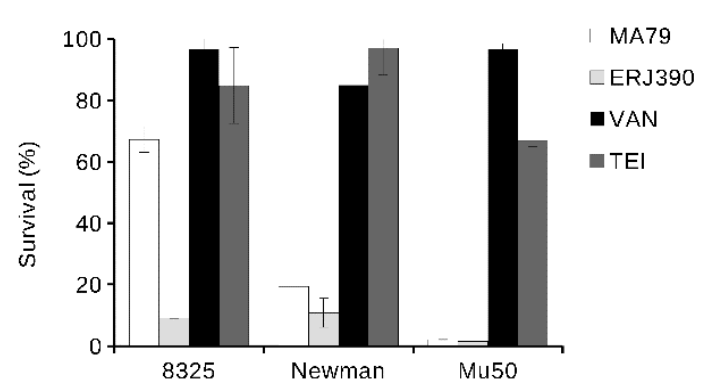

(b)

Figure 4. Killing of cells of different S. aureus strains during one hour of treatment by antibiotics vancomycin (VAN), teicoplanin (TEI), MA79, and ERJ390 pre-grown to exponential (a) or stationary (b) growth phases. The antibiotics were used at a concentration exceeding the MIC 5-fold and 50-fold against $S$. aureus cells in exponential or stationary growth phases, respectively.

\subsection{MA79 and ERJ390 Do Not Induce S. aureus Biofilm Formation}

Antibiotics at subinhibitory concentrations can induce biofilm formation in bacteria [10]. Therefore, the ability of MA79 and ERJ390 to induce biofilm formation in S. aureus strains 8325, Newman, and Mu50 was investigated. Under our experimental conditions, biofilm formation was not induced or abrogated at subinhibitory concentrations of VAN [11]. On the contrary, TEI strongly induced biofilm formation in 8325 and to a lesser extent in Newman (Figure 5). Mu50 did not form biofilm under our growth conditions. MA79 and ERJ390 inhibited biofilm formation at subinhibitory concentrations. Thus, MA79 and ERJ390 did not induce S. aureus biofilm formation but prevented it at subinhibitory concentrations.
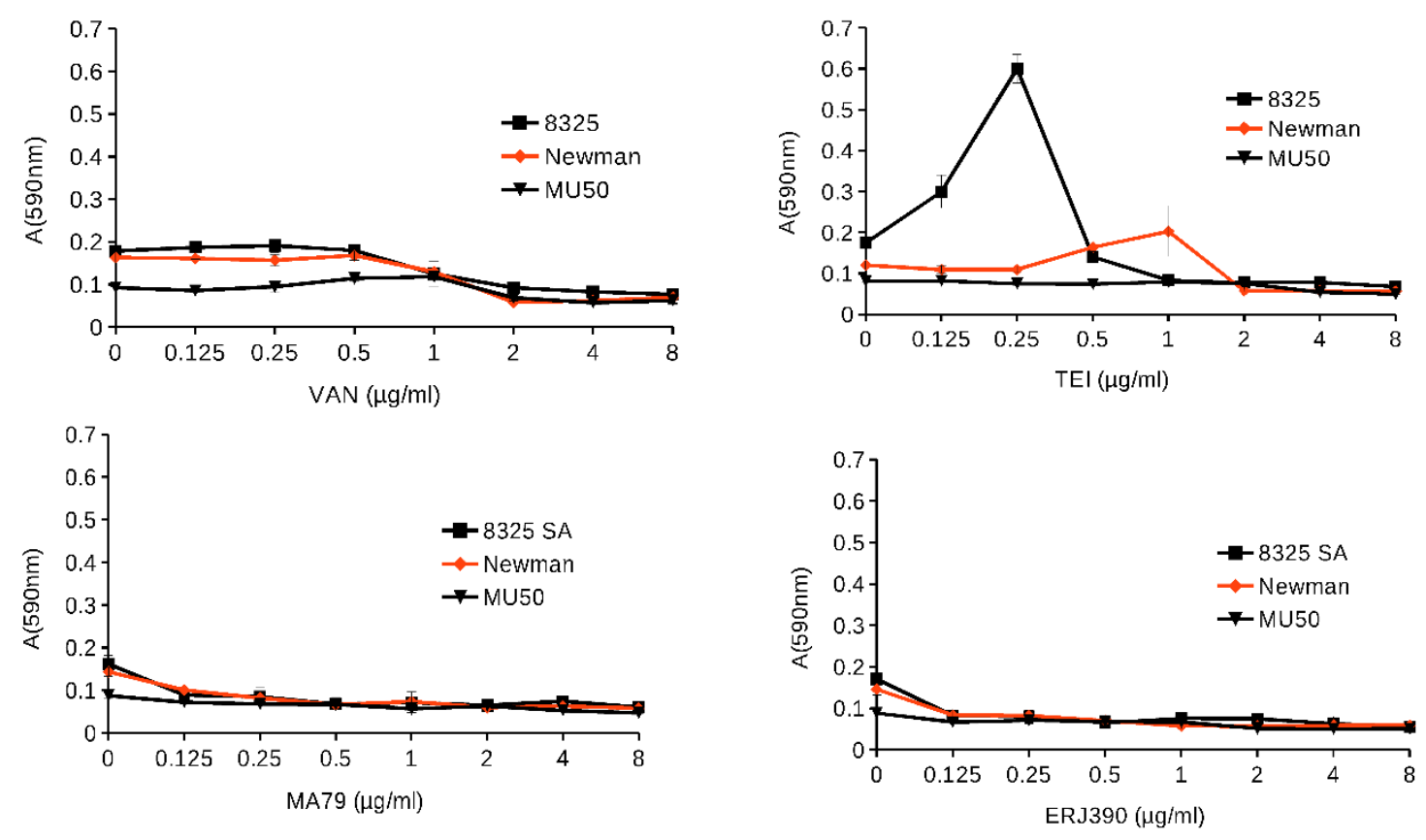

Figure 5. Biofilm formation of S. aureus in the presence of different concentrations of the VAN, TEI, MA79, and ERJ390. 


\subsection{ERJ390 Eradicates S. aureus Biofilm}

The treatment of $S$. aureus biofilms is challenging because even the most potent antibiotics have little effect on established biofilms [12-14]. In the present study, biofilms of $S$. aureus 8325 established overnight were treated with MA79, ERJ390, VAN, or TEI and cell viability was monitored by MTT staining (see Figure 6). MTT assay was employed for the quantification of biofilm biomass and metabolic activity [15]. MTT is a yellowish aqueous solution and yields a water-insoluble violet-blue formazan that is formed due to reduction by dehydrogenases and reducing agents present in metabolically active cells. Biofilm metabolic activity has been previously shown to be proportional to the production of formazan by measuring absorbance at $\mathrm{A}_{450 \mathrm{~nm}}$ [15].

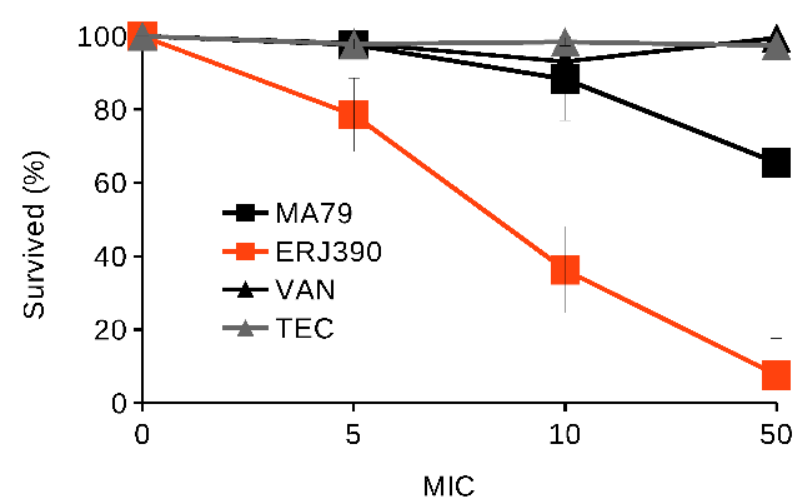

(a)

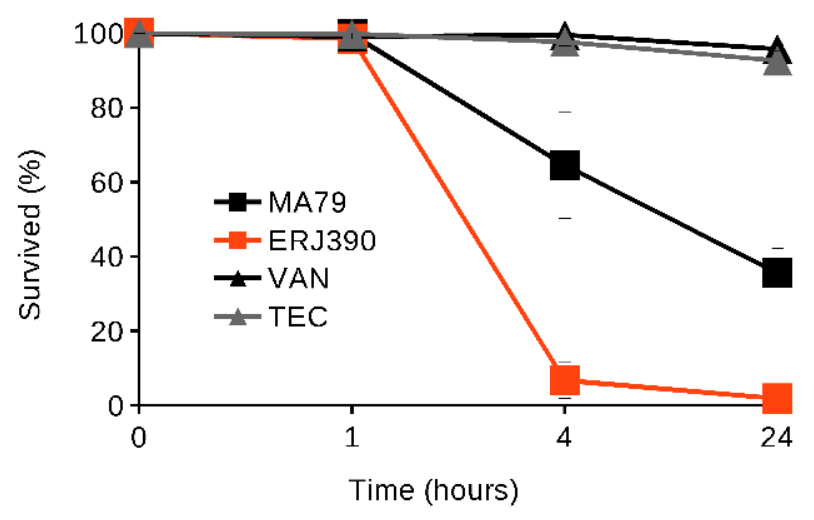

(b)

Figure 6. Killing of S. aureus cells in biofilm at different concentrations of antibiotics above MICs after four hours of incubation (a). Killing of $S$. aureus cells in biofilm at concentrations of the antibiotics 50 times higher than the MICs after different incubation times (b).

While VAN and TEI were unable to kill the bacteria in the biofilm, MA79 killed about $30 \%$ of the bacteria at a concentration 50 times higher than the MIC, and ERJ390 killed almost all the cells in the biofilm after four hours of incubation with the antibiotic (see Figure 6a). After extending the antibiotic treatment to $24 \mathrm{~h}$, all bacterial cells in the biofilm were killed by ERJ390 and 60\% of the cells were killed by MA79 (see Figure $6 \mathrm{~b}$ ). Therefore, this result shows the potential of the novel glycopeptide antibiotics to eradicate biofilms.

\subsection{MA79 and ERJ390 Do Not Cause Resistance Selection}

The development of resistance to commonly used antibiotics is the major drawback of antibiotic use [16]. We investigated the potential of MA79 and ERJ390 to select resistant mutants in S. aureus. No colonies appeared on plates containing MA79 or ERJ390, regardless of whether the bacteria were pre-incubated with sub-inhibitory concentrations of the respective antibiotics (see Figure 7a,b). No mutants with elevated MICs of MA79 or ERJ390 were selected even after 10 days of bacterial growth in the presence of subinhibitory concentrations of the antibiotics. 
a

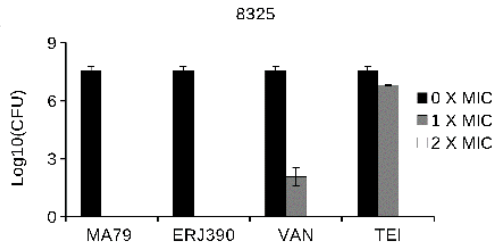

b

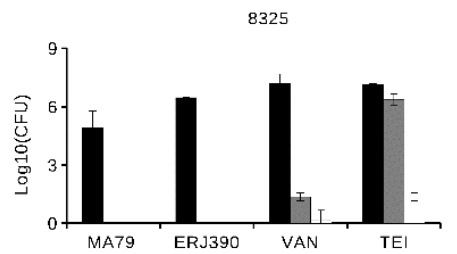

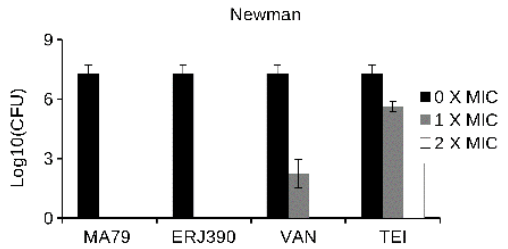

Newman

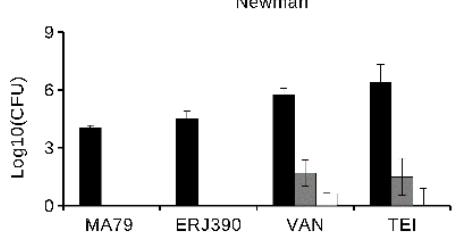

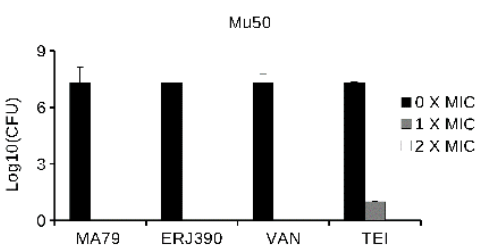

Mu50

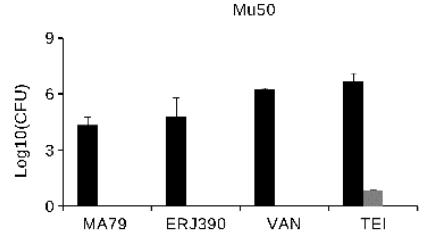

Figure 7. Selection of S. aureus 8325, Newman, and Mu50 resistant mutants, with (a) or without (b) prior incubation with subinhibitory concentration of antibiotics. The graphs show the number of colonies that appeared on the BHI agar plates with the respective antibiotic at 0 -fold, 1-fold, or 2-fold MIC.

\section{Discussion}

In the last decade, the modification of the glycopeptide antibiotics vancomycin, teicoplanin, and ristocetin with different side chains, including hydrophobic and lipophilic moieties, have yielded new antibiotics that exhibit enhanced antibacterial activity and, in certain cases, high and broad-spectrum antiviral activity [17]. Three semi-synthetic lipoglycopeptide antibiotics, namely, telavancin, dalbavancin, and oritavancin, were approved for clinical use. Nevertheless, research has been conducted to further improve glycopeptide antibiotics [18]. Maleimido teicoplanin pseudoaglycone with two propylthiol groups, MA79, and teicoplanin pseudoaglycone derivative with a lipophilic n-decyl chain, ERJ390 (see Figure 1), have both been reported as effective antibiotics against various Gram-positive bacteria, including bacteria highly resistant to vancomycin and teicoplanin [9]. However, a more detailed review of the antimicrobial activity of these antibiotics was lacking.

Our present experimental data demonstrate the bactericidal activity of MA79 and especially ERJ390 against $S$. aureus cells in the exponential and late stationary phase. The semisynthetic lipoglycopeptide antibiotic oritavancin, recently approved for clinical use, kills nondividing S. aureus cells, whereas VAN and dalbavancin do not $[19,20]$. The bacteriolytic activity of oritavancin against $S$. aureus cells in the stationary growth phase was effective at a concentration that exceeded the MIC by more than 100-200-fold. This is a much higher concentration than in the case of MA79 and ERJ390. Thus, the bacteriolytic activity of MA79 and ERJ390 appears to be equal to or even higher than that demonstrated for oritavancin [19]. Moreover, ERJ390 is more efficient than MA79 (Figures 2 and 3).

The killing of $S$. aureus cells in biofilm has been demonstrated for telavancin, oritavancin, and dalbavancin [12,21,22]. However, none of the antibiotics were able to completely kill the bacterial cells within the biofilms, even at concentrations exceeding 100 times the MIC. In comparison, ERJ390 was more efficient in killing bacterial cells within the biofilm and was able to kill all bacterial cells in the biofilm within $24 \mathrm{~h}$ at concentrations greater than 50 times the MIC (see Figure 6).

The observed activity of ERJ390 and MA79 against S. aureus cells in the stationary growth phase and in biofilms can be explained by the ability of the antibiotics to bind to the membrane. For oritavancin and telavancin, it has been demonstrated that their lipophilic side chains can anchor the antibiotics to bacterial membranes, leading to membrane depolarization and disruption, thus facilitating the bacteriolytic activity of glycopeptide antibiotics against non-dividing bacterial cells [17,23-25]. ERJ390 possessed a stronger killing activity than MA79. The interaction of ERJ390 with the membrane could be stronger than that of MA79, which was supported by the increased ability of ERJ390 to supplant fluorescently labeled teicoplanin from the cells [9]. This could explain the high killing efficiency of ERJ390. 
The increased activity of ERJ390 may also be explained by the self-aggregation of the glycopeptide antibiotic [7]. It is known that self-aggregation enhances the interaction of oritavancin with the membrane and increases the bacteriolytic activity [26]. Self-aggregation of MA79 was not reported, which partly explains the lower activity of MA79 in killing non-dividing cells.

It is known that VAN, TEI, and dalbavancin can select $S$. aureus mutants with 16-128-fold increased resistance by multiple incubation steps with the antibiotics $[27,28]$. The resistance selection potential of MA79 and ERJ390 was not observed, suggesting that these antibiotics may be safe in terms of resistance development. The only reduction in susceptibility to MA79 and ERJ390 reported to date was observed in S. aureus expressing the membrane protein VanZ [29]. The expression of VanZ reduced the susceptibility of S. aureus to all lipoglycopeptide antibiotics. The acquisition and spread of VanZ genes in S. aureus may become a problem in the future. The encoding van $\mathrm{Z}$ gene, as part of the vanA gene cluster, has occasionally been transferred to $S$. aureus by transposons from enterococci, resulting in highly vancomycin-resistant strains [30]. Although the frequency of such an event appears to be low due to the high fitness cost of vanHAX-mediated resistance in $S$. aureus, vancomycin-resistant staphylococcal strains may be precursors for the generation of vanZ-bearing mobile genetic elements that can interfere with the action of semisynthetic lipoglycopeptide antibiotics.

\section{Materials and Methods}

\subsection{Strains}

S. aureus strains 8325, Mu50, and Newman were kindly provided by Dr. Malcolm J Horsburgh. S. aureus strain 8325 [31] is considered as the reference genome in the NCBI database $\left(\mathrm{MIC}_{\mathrm{VAN}}=1 \mu \mathrm{g} / \mathrm{mL} ; \mathrm{MIC}_{\mathrm{TEI}}=2 \mu \mathrm{g} / \mathrm{mL} ; \mathrm{MIC}_{\mathrm{MA79}}=0.5 \mu \mathrm{g} / \mathrm{mL} ; \mathrm{MIC}_{\text {ERJ390 }}=0.25 \mu \mathrm{g} / \mathrm{mL}\right)$. Mu50 was the first MRSA strain with vancomycin resistance isolated in 1997 [32] $\left(\mathrm{MIC}_{\mathrm{VAN}}=4 \mu \mathrm{g} / \mathrm{mL} ; \mathrm{MIC}_{\mathrm{TEI}}=4 \mu \mathrm{g} / \mathrm{mL} ; \mathrm{MIC}_{\mathrm{MA79}}=0.5 \mu \mathrm{g} / \mathrm{mL} ; \mathrm{MIC}_{\mathrm{ERJ} 390}=0.25 \mu \mathrm{g} / \mathrm{mL}\right)$. S. aureus strain Newman [33] $\left(\mathrm{MIC}_{\mathrm{VAN}}=0.5 \mu \mathrm{g} / \mathrm{mL} ; \mathrm{MIC}_{\mathrm{TEI}}=0.25 \mu \mathrm{g} / \mathrm{mL} ; \mathrm{MIC}_{\mathrm{MA79}}=0.5 \mu \mathrm{g} / \mathrm{mL}\right.$; $\mathrm{MIC}_{\text {ERJ390 }}=0.25 \mu \mathrm{g} / \mathrm{mL}$ ) was isolated in 1952 from a human infection and displays robust virulence properties in animal models of disease and has already been extensively analyzed for its molecular traits of staphylococcal pathogenesis. The absence of drug resistance genes reflects the general antibiotic-susceptible phenotype of $S$. aureus Newman. S. aureus strains were pre-grown overnight on brain-heart infusion (BHI) agar plates at $37^{\circ} \mathrm{C}$ prior to the experiments.

\subsection{Antibiotics}

Vancomycin (V2002) and teicoplanin (T0578) were bought from Sigma-Aldrich ${ }^{\circledR}$ (St. Louis, MO, USA). MA79 and ERJ390 were synthesized as previously described [6,7]. For each experiment, new stock solutions of antibiotics were prepared.

The MA79 synthesis protocol is shown in Figure 8.

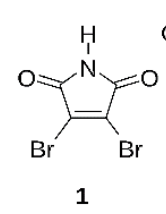

1

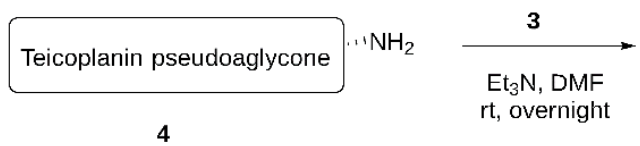

2
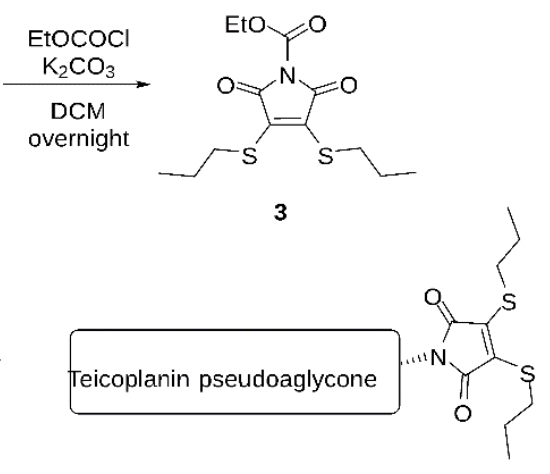

MA79

Figure 8. Schematic representation of MA79 synthesis. 
A. Maleimide bis- $n$-propylsulfide (2)

To a stirred solution of 2,3-dibromomaleimide (1) (510 mg, $2.0 \mathrm{mmol})$ in $\mathrm{CH}_{2} \mathrm{Cl}_{2}$ $(30 \mathrm{~mL}), \mathrm{Et}_{3} \mathrm{~N}(4.0 \mathrm{mmol})$ and propyl mercaptane $(380 \mu \mathrm{L}, 4.2 \mathrm{mmol})$ were added under argon atmosphere and stirred for $3 \mathrm{~h}$ at room temperature. The reaction mixture was evaporated, and the crude product was purified by flash silica gel chromatography in $n$-hexane:ethyl acetate $=9: 1$ to give $2(430 \mathrm{mg}, 87 \%)$ as a yellow syrup. ${ }^{1} \mathrm{H}$ NMR $(400 \mathrm{MHz}$, $\left.\mathrm{CDCl}_{3}\right) \delta 7.77(1 \mathrm{H}, \mathrm{s}, \mathrm{NH}), 3.28-3.25\left(4 \mathrm{H}, \mathrm{m}, 2 \times \mathrm{SCH}_{2}\right), 1.73-1.66\left(4 \mathrm{H}, \mathrm{m}, 2 \times \mathrm{CH}_{2}\right)$, 1.06-1.02 (6H, m, $\left.2 \times \mathrm{CH}_{3}\right) ;{ }^{13} \mathrm{C} \mathrm{NMR}\left(100 \mathrm{MHz}, \mathrm{CDCl}_{3}\right) \delta 166.3(2 \mathrm{C}, 2 \times \mathrm{C}=\mathrm{O}), 137.2(2 \mathrm{C}$, $\mathrm{C}=\mathrm{C}), 33.6\left(2 \mathrm{C}, 2 \times \mathrm{CH}_{2}\right), 23.8\left(2 \mathrm{C}, 2 \times \mathrm{SCH}_{2}\right), 13.1\left(2 \mathrm{C}, 2 \times \mathrm{CH}_{3}\right)$; Analysis Calculated for $\mathrm{C}_{10} \mathrm{H}_{15} \mathrm{NO}_{2} \mathrm{~S}_{2} \mathrm{C} 48.95, \mathrm{H}$ 6.16, N 5.71, O 13.04, S 26.14. Found: C 48.18, H 5.70, S 26.01.

B. $\quad N$-Ethoxycarbonyl maleimide bis-n-propylsulfide (3)

To a stirred solution of maleimide bis-sulfide $2(1.0 \mathrm{mmol})$ in dry acetone $(20 \mathrm{~mL})$, $\mathrm{K}_{2} \mathrm{CO}_{3}(1.2 \mathrm{mmol})$ and ethyl chloroformate $(1.2 \mathrm{mmol})$ were added under argon atmosphere and stirred for $3 \mathrm{~h}$ at room temperature. The reaction mixture was diluted with $\mathrm{CH}_{2} \mathrm{Cl}_{2}$, filtered through a pad of Celite, and evaporated. The crude product was used for further steps without purification.

\section{MA79}

To a stirred solution of teicoplanin pseudoaglycone $(140 \mathrm{mg}, 0.1 \mathrm{mmol})$ in dry DMF ( $5 \mathrm{~mL})$, N-ethoxycarbonyl maleimide bis-sulfides $3(40 \mathrm{mg}, 0.14 \mathrm{mmol})$ and $\mathrm{Et}_{3} \mathrm{~N}(0.1 \mathrm{mmol})$ were added under argon atmosphere and stirred overnight at room temperature. The reaction mixture was evaporated, and the crude product was purified by silica gel chromatography in toluene:methanol $=9: 1$ to give $\mathbf{8 d}(110 \mathrm{mg}, 66 \%)$ as a yellow powder. MALDI-TOF MS: $[\mathrm{M}+\mathrm{Na}]^{+}=1651.02 \mathrm{~m} / \mathrm{z}$. Calculated for $\mathrm{C}_{76} \mathrm{H}_{70} \mathrm{Cl}_{2} \mathrm{~N}_{8} \mathrm{O}_{25} \mathrm{~S}_{2} \mathrm{Na} 1651.32 \mathrm{~m} / \mathrm{z}$.

See Figure 9 for the ERJ390 synthesis protocol.

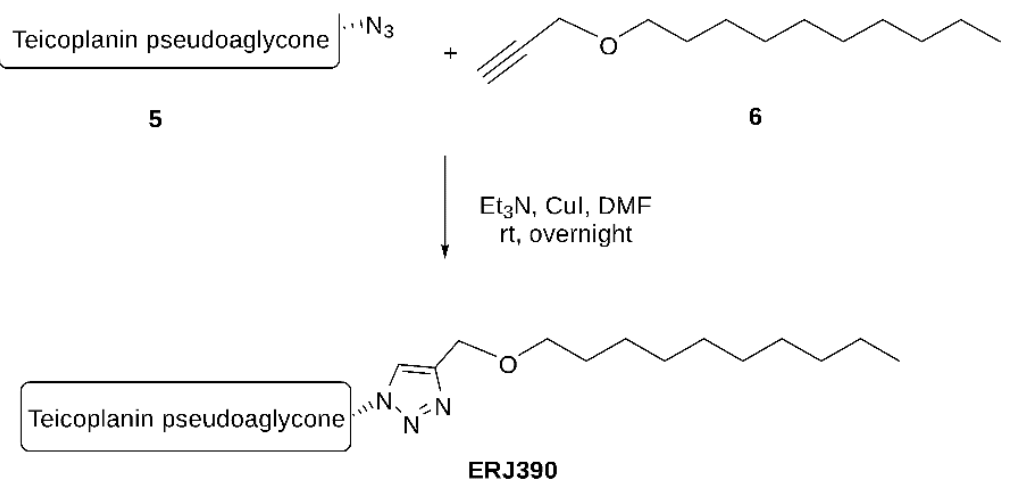

Figure 9. Schematic representation of the ERJ390 synthesis.

To a stirred solution of teicoplanin pseudoaglycone azide $(140 \mathrm{mg}, 0.1 \mathrm{mmol})$ in dry DMF ( $5 \mathrm{~mL}), n$-decyl propargyl ether $6(24 \mathrm{mg}, 0.13 \mathrm{mmol}), \mathrm{Et}_{3} \mathrm{~N}$ (1.0 equiv.), and $\mathrm{Cu}(\mathrm{I}) \mathrm{I}(20-30 \mathrm{~mol} \%)$ were added under an argon atmosphere and stirred for overnight at room temperature. The reaction mixture was concentrated, and the crude product was purified by flash chromatography in toluene: $\mathrm{MeOH}=1: 1$. (+1.0 v/v\% acetic acid). Yield: $115 \mathrm{mg}, 71 \%$.

\subsection{Susceptibility Testing}

Minimum inhibitory concentrations (MICs) were determined by the microbroth dilution method in Mueller-Hinton (MH) medium according to the EUCAST guidelines (ISO 20776). Overnight cultures of $S$. aureus pre-grown on BHI agar at $37^{\circ} \mathrm{C}$ were resuspended in $0.9 \% \mathrm{NaCl}$ solution to $\mathrm{McFarland}=0.5$. Five microliters of the resuspended S. aureus cells were pipetted into each well of a 96-well plate (Thermo Scientific ${ }^{\text {TM }} 130188$ BioLite 96 Well Multidish, Waltham, MA, USA) containing MH medium with concentration of antibiotics. Ranges of antibiotic concentrations tested were 0.0156-1024 $\mu \mathrm{g} / \mathrm{mL}$. Absorbance 
was measured at $\mathrm{A}_{600 \mathrm{~nm}}$, using a BioTek ${ }^{\circledR}$ Synergy HT spectrophotometer after $24 \mathrm{~h}$ of bacteria incubation in $\mathrm{MH}$ medium in 96 -well plates at $37^{\circ} \mathrm{C}$. Each MIC test was performed three times in triplicate. Bacterial growth was considered to be completely inhibited by the antibiotic if the absorbance value was lower than the highest absorbance value of the wells containing only growth medium.

\subsection{S. aureus Killing in Exponential and Late Stationary Growth Phases by the Antibiotics}

S. aureus 8325 was pre-grown in $\mathrm{MH}$ medium at $37^{\circ} \mathrm{C}$ to $\mathrm{A}_{600 \mathrm{~nm}}=0.6$ or grown for $18 \mathrm{~h}$ until stationary phase was reached (see Figure S1). Glycopeptide antibiotics were added to the pre-cultured bacteria at concentrations 5,10 , and 50 times higher than the respective MICs and incubated at $37^{\circ} \mathrm{C}$ for $1 \mathrm{~h}$. Incubated bacteria without antibiotic were used as negative controls. The number of colony-forming units (CFUs) in antibiotic-treated or untreated samples was determined by spreading $10 \mu \mathrm{L}$ of cultures diluted $10^{1}-10^{8}$-fold in $0.9 \% \mathrm{NaCl}$ on brain-heart infusion (BHI) agar plates. The number of CFUs in the untreated sample was set as $100 \%$ of the surviving bacterial cells. Each experiment was performed in triplicate and repeated three times. The time course of killing S. aureus 8325 in the exponential or stationary growth phase was performed at concentrations 5 and 50 times higher than the MIC, respectively, and analyzed after $0,1,4$, and $24 \mathrm{~h}$ of incubation at $37^{\circ} \mathrm{C}$. Killing of $S$. aureus 8325 , Newman, and Mu50 by antibiotics was analyzed after $1 \mathrm{~h}$ of incubation of the bacteria at 5 and 50-fold higher MICs for bacteria in the exponential and stationary growth phases, respectively.

\subsection{S. aureus Biofilm Formation in the Presence of Glycopeptide Antibiotics}

Biofilms of $S$. aureus were established in 96-well plates after 24-h bacterial growth in tryptic soy broth (TSB) at $37^{\circ} \mathrm{C}$ [34] in the presence of the antibiotics: MA79, ERJ390, VAN, and TEI at concentrations of $0,0.125,0.25,0.5,1,2,4$, and $8 \mu \mathrm{g} / \mathrm{mL}$. After $24 \mathrm{~h}$ of incubation, the plates were carefully rinsed with water 3 times to remove non-adherent cells. Cells remaining in the wells were stained with $50 \mu \mathrm{L}$ of $1 \%$ crystal violet for $15 \mathrm{~min}$, then carefully rinsed with water 5 times and air dried. Crystal violet was recovered from the stained cells by adding $100 \mu \mathrm{L}$ of a $96 \%$ ethanol solution. The absorbance of the plate was then measured at $A_{590 \mathrm{~nm}}$ using a TECAN Infinite Pro spectrophotometer. Each experiment was performed three times in triplicate.

\subsection{Bacteria Killing in S. aureus Biofilm}

The biofilm of $S$. aureus 8325 was established in 96-well plates after $24 \mathrm{~h}$ of bacterial growth in tryptic soy broth medium (TSB) at $37^{\circ} \mathrm{C}$ (TSB) [34]. The biofilms were washed 3 times with $0.9 \% \mathrm{NaCl}$. Then, $100 \mu \mathrm{L}$ of fresh TSB medium without or with antibiotics at concentrations 5, 10, and 50 times higher than the MICs was added to the biofilms. After incubating the biofilm with the antibiotics at $37^{\circ} \mathrm{C}$ for $4 \mathrm{~h}$, the biofilms were washed three times with $0.9 \% \mathrm{NaCl}$ and then stained with $0.2 \%$ MTT for $1 \mathrm{~h}$ at $37^{\circ} \mathrm{C}$. The MTT assay was used to quantify biofilm biomass and metabolic activity [15]. The absorbance was measured at $\mathrm{A}_{450 \mathrm{~nm}}$ using TECAN Infinite ${ }^{\circledR}$ Pro spectrophotometer. Absorbance values of biofilms not treated with antibiotics were set as 100\% of surviving cells. Each experiment was performed three times with four replicates each time. Killing of bacteria in the biofilm occurred at 1, 4, and $24 \mathrm{~h}$ when antibiotic concentrations were 50-fold higher than MICs.

\subsection{Selection of Resistance}

S. aureus strains 8325, Newman, and Mu50 were grown at $37^{\circ} \mathrm{C}$ in $2 \mathrm{~mL}$ of $\mathrm{MH}$ medium to $\mathrm{A}_{600 \mathrm{~nm}}=0.6$ in the absence or presence of half of MIC of MA79, ERJ390, VAN, or TEC. A total of $100 \mu \mathrm{L}$ of pre-grown cells was plated on BHI agar plates with antibiotics at concentration 0,1 , or 2 times exceeding MICs. Colonies were counted after $24 \mathrm{~h}$ of incubation at $37^{\circ} \mathrm{C}$. The logarithmic values of numbers of appeared colonies (CFU) were compared. The experiment was repeated three times. Since we have not selected MA79- and ERJ390-resistant mutants by this approach, we increased the time of $S$. aureus incubation 
with half MIC of MA79 and ERJ390 for 10 days, diluting bacteria 100 times into fresh BHI medium with half MIC of the antibiotics every $12 \mathrm{~h}$. MICs of the antibiotics against colonies that appeared on the plates in the presence of the highest antibiotic concentration were determined (see Table S1).

\section{Conclusions}

MA79 and ERJ390 are novel semisynthetic glycopeptides with improved activity against Gram-positive bacteria compared to VAN and TEC. They can overcome multiple glycopeptide resistance mechanisms and are significantly less susceptible to the development of resistance. The antibacterial activity of MA79 and ERJ390 is not solely dependent on interaction with D-Ala-D-Ala and could involve binding to the bacterial cell membrane. The mechanism of binding of the new glycopeptides to the cell membrane might be different from that of teicoplanin and dalbavancin. Further studies are required to discover the exact mechanisms of action of MA79 and ERJ390.

Supplementary Materials: The following are available online at https:/ / www.mdpi.com/article/ 10.3390/ph14111182/s1, Figure S1: Growth curves of Staphylococcus aureus strains used in the study, Table S1: MICs of the antibiotics against wild-type (WT) Staphylococcus aureus strains and mutants selected in resistance selection experiments.

Author Contributions: Conceptualization, V.V., A.M., G.B.N., A.B. and P.H.; methodology, V.V., L.Z. and Z.S.; validation, V.V.; formal analysis, V.V. and Z.S.; resources, V.V., G.B.N., A.B. and P.H.; writing-original draft preparation, V.V. and A.M.; writing-review and editing, V.V., A.M., A.B., P.H. and G.B.N.; visualization, V.V. and A.M.; supervision, V.V., A.B. and P.H.; project administration, V.V., G.B.N., A.B. and P.H.; funding acquisition, V.V., G.B.N., A.B. and P.H. All authors have read and agreed to the published version of the manuscript.

Funding: This work was supported by the Czech Health Research Council project NV15-28807A, by the project BIOCEV-Biotechnology and Biomedicine Center of the Academy of Sciences and Charles University (CZ.1.05/1.1.00/02.010) from the European Regional Development Fund in the Czech Republic and by the EU, and co-financed by the European Regional Development Fund under the project GINOP-2.3.2-15-2016-00008. The work was supported by private funding from V.V.

Institutional Review Board Statement: Not applicable.

Informed Consent Statement: Not applicable.

Data Availability Statement: Data is contained within the article and supplementary material.

Conflicts of Interest: The authors declare no conflict of interest.

\section{References}

1. Turner, N.A.; Sharma-Kuinkel, B.K.; Maskarinec, S.A.; Eichenberger, E.M.; Shah, P.P.; Carugati, M.; Holland, T.L.; Fowler, V.G. Methicillin-resistant Staphylococcus aureus: An overview of basic and clinical research. Nat. Rev. Microbiol. 2019, 17, $203-218$. [CrossRef] [PubMed]

2. Beauregard, D.A.; Williams, D.H.; Gwynn, M.N.; Knowles, D.J.C. Dimerization and membrane anchors in extracellular targeting of vancomycin group antibiotics. Antimicrob. Agents Chemother. 1995, 39, 781-785. [CrossRef] [PubMed]

3. Economou, N.J.; Zentner, I.J.; Lazo, E.; Jakoncic, J.; Stojanoff, V.; Weeks, S.D.; Grasty, K.C.; Cocklin, S.; Loll, P.J. Structure of the complex between teicoplanin and a bacterial cell-wall peptide: Use of a carrier-protein approach. Acta Crystallogr. Sect. D Biol. Crystallogr. 2013, 69, 520-533. [CrossRef] [PubMed]

4. Zeng, D.; Debabov, D.; Hartsell, T.L.; Cano, R.J.; Adams, S.; Schuyler, J.A.; McMillan, R.; Pace, J.L. Approved glycopeptide antibacterial drugs: Mechanism of action and resistance. Cold Spring Harb. Perspect. Med. 2016, 6, a026989. [CrossRef]

5. Cheung, A.L.; Bayer, A.S.; Zhang, G.; Gresham, H.; Xiong, Y.Q. Regulation of virulence determinants in vitro and in vivo in Staphylococcus aureus. FEMS Immunol. Med. Microbiol. 2004, 40, 1-9. [CrossRef]

6. Pintér, G.; Batta, G.; Kéki, S.; Mándi, A.; Komáromi, I.; Takács-Novák, K.; Sztaricskai, F.; Roth, E.; Ostorházi, E.; Rozgonyi, F.; et al. Diazo transfer-click reaction route to new, lipophilic teicoplanin and ristocetin aglycon derivatives with high antibacterial and anti-influenza virus activity: An aggregation and receptor binding study. J. Med. Chem. 2009, 52, 6053-6061. [CrossRef] [PubMed]

7. Csávás, M.; Miskovics, A.; Szúcs, Z.; Rőth, E.; Nagy, Z.L.; Bereczki, I.; Herczeg, M.; Batta, G.; Nemes-Nikodém, É.; Ostorházi, E.; et al. Synthesis and antibacterial evaluation of some teicoplanin pseudoaglycon derivatives containing alkyl-and arylthiosubstituted maleimides. J. Antibiot. 2015, 68, 579-585. [CrossRef] 
8. Szúcs, Z.; Kelemen, V.; Le Thai, S.; Csávás, M.; Rőth, E.; Batta, G.; Stevaert, A.; Vanderlinden, E.; Naesens, L.; Herczegh, P.; et al. Structure-activity relationship studies of lipophilic teicoplanin pseudoaglycon derivatives as new anti-influenza virus agents. Eur. J. Med. Chem. 2018, 157, 1017-1030. [CrossRef]

9. Vimberg, V.; Gazak, R.; Szúcs, Z.; Borbás, A.; Herczegh, P.; Cavanagh, J.P.; Zieglerova, L.; Závora, J.; Adámková, V.; Balikova Novotna, G. Fluorescence assay to predict activity of the glycopeptide antibiotics. J. Antibiot. 2019, 72, $114-117$. [CrossRef]

10. Kaplan, J.B. Antibiotic-induced biofilm formation. Int. J. Artif. Organs 2011, 34, 737-751. [CrossRef]

11. Mirani, Z.A.; Jamil, N. Effect of sub-lethal doses of vancomycin and oxacillin on biofilm formation by vancomycin intermediate resistant Staphylococcus aureus. J. Basic Microbiol. 2011, 51, 191-195. [CrossRef]

12. El-Azizi, M.; Rao, S.; Kanchanapoom, T.; Khardori, N. In vitro activity of vancomycin, quinupristin/dalfopristin, and linezolid against intact and disrupted biofilms of staphylococci. Ann. Clin. Microbiol. Antimicrob. 2005, 4, 2. [CrossRef] [PubMed]

13. Pozzi, C.; Waters, E.M.; Rudkin, J.K.; Schaeffer, C.R.; Lohan, A.J.; Tong, P.; Loftus, B.J.; Pier, G.B.; Fey, P.D.; Massey, R.C.; et al. Methicillin resistance alters the biofilm phenotype and attenuates virulence in Staphylococcus aureus device-associated infections. PLoS Pathog. 2012, 8, e1002626. [CrossRef] [PubMed]

14. Omar, A.; Wright, J.B.; Schultz, G.; Burrell, R.; Nadworny, P. Microbial biofilms and chronic wounds. Microorganisms 2017, 5, 9. [CrossRef]

15. Miao, J.; Lin, S.; Soteyome, T.; Peters, B.M.; Li, Y.; Chen, H.; Su, J.; Li, L.; Li, B.; Xu, Z.; et al. Biofilm Formation of Staphylococcus aureus under Food Heat Processing Conditions: First Report on CML Production within Biofilm. Sci. Rep. 2019, 9, 1312. [CrossRef] [PubMed]

16. Gwynn, M.N.; Portnoy, A.; Rittenhouse, S.F.; Payne, D.J. Challenges of antibacterial discovery revisited. Ann. N. Y. Acad. Sci. 2010, 1213, 5-19. [CrossRef]

17. Blaskovich, M.A.T.; Hansford, K.A.; Butler, M.S.; Jia, Z.; Mark, A.E.; Cooper, M.A. Developments in Glycopeptide Antibiotics. ACS Infect. Dis. 2018, 4, 715-735. [CrossRef]

18. Mühlberg, E.; Umstätter, F.; Kleist, C.; Domhan, C.; Mier, W.; Uhl, P. Renaissance of vancomycin: Approaches for breaking antibiotic resistance in multidrug-resistant bacteria. Can. J. Microbiol. 2020, 66, 11-16. [CrossRef]

19. Belley, A.; Neesham-Grenon, E.; McKay, G.; Arhin, F.F.; Harris, R.; Beveridge, T.; Parr, T.R.; Moeck, G. Oritavancin kills stationary-phase and biofilm Staphylococcus aureus cells in vitro. Antimicrob. Agents Chemother. 2009, 53, 918-925. [CrossRef]

20. Belley, A.; Lalonde Seguin, D.; Arhin, F.; Moeck, G. Comparative in vitro activities of oritavancin, dalbavancin, and vancomycin against methicillin-resistant Staphylococcus aureus isolates in a nondividing state. Antimicrob. Agents Chemother. 2016, 60, 4342-4345 [CrossRef]

21. Chan, C.; Hardin, T.C.; Smart, J.I. A review of telavancin activity in in vitro biofilms and animal models of biofilm-associated infections. Future Microbiol. 2015, 10, 1325-1338. [CrossRef] [PubMed]

22. Meeker, D.G.; Beenken, K.E.; Mills, W.B.; Loughran, A.J.; Spencer, H.J.; Lynn, W.B.; Smeltzer, M.S. Evaluation of Antibiotics Active Against methicillin-resistant Staphylococcus aureus based on activity in an established biofilm. Antimicrob. Agents Chemother. 2016, 60, 5688-5694. [CrossRef] [PubMed]

23. Zhanel, G.G.; Calic, D.; Schweizer, F.; Zelenitsky, S.; Adam, H.; Lagac-Wiens, P.R.S.; Rubinstein, E.; Gin, A.S.; Hoban, D.J.; Karlowsky, J.A. New lipoglycopeptides: A comparative review of dalbavancin, oritavancin and telavancin. Drugs 2010, 70, 859-886. [CrossRef] [PubMed]

24. Zhanel, G.G.; Schweizer, F.; Karlowsky, J.A. Oritavancin: Mechanism of action. Clin. Infect. Dis. 2012, 54, S214-S219. [CrossRef]

25. Song, Y.; Lunde, C.S.; Benton, B.M.; Wilkinson, B.J. Further insights into the mode of action of the lipoglycopeptide telavancin through global gene expression studies. Antimicrob. Agents Chemother. 2012, 56, 3157-3164. [CrossRef]

26. Cheng, M.; Ziora, Z.M.; Hansford, K.A.; Blaskovich, M.A.; Butler, M.S.; Cooper, M.A. Anti-cooperative ligand binding and dimerisation in the glycopeptide antibiotic dalbavancin. Org. Biomol. Chem. 2014, 12, 2568-2575. [CrossRef] [PubMed]

27. Berscheid, A.; François, P.; Strittmatter, A.; Gottschalk, G.; Schrenzel, J.; Sass, P.; Bierbaum, G. Generation of a vancomycinintermediate Staphylococcus aureus (VISA) strain by two amino acid exchanges in VraS. J. Antimicrob. Chemother. 2014, 69, 3190-3198. [CrossRef]

28. Werth, B.J.; Jain, R.; Hahn, A.; Cummings, L.; Weaver, T.; Waalkes, A.; Sengupta, D.; Salipante, S.J.; Rakita, R.M.; Butler-Wu, S.M. Emergence of dalbavancin non-susceptible, vancomycin-intermediate Staphylococcus aureus (VISA) after treatment of MRSA central line-associated bloodstream infection with a dalbavancin- and vancomycin-containing regimen. Clin. Microbiol. Infect. 2018, 24, 429.e1-429.e5. [CrossRef]

29. Vimberg, V.; Zieglerová, L.; Buriánková, K.; Branny, P.; Balíková Novotná, G. VanZ Reduces the Binding of Lipoglycopeptide Antibiotics to Staphylococcus aureus and Streptococcus pneumoniae Cells. Front. Microbiol. 2020, 11, 566. [CrossRef]

30. Cong, Y.; Yang, S.; Rao, X. Vancomycin resistant Staphylococcus aureus infections: A review of case updating and clinical features. J. Adv. Res. 2020, 21, 169-176. [CrossRef]

31. Gillaspy, A.F.; Worrell, V.; Orvis, J.; Roe, B.A.; Dyer, D.W.; Iandolo, J.J. The Staphylococcus aureus NCTC 8325 Genome. In Gram-Positive Pathogens, 2nd ed.; American Society of Microbiology: Washington, DC, USA, 2006; pp. $381-412$. 
32. Hiramatsu, K. The emergence of Staphylococcus aureus with reduced susceptibility to vancomycin in Japan. Am. J. Med. 1998, 104, 7S-10S. [CrossRef]

33. Baba, T.; Bae, T.; Schneewind, O.; Takeuchi, F.; Hiramatsu, K. Genome sequence of Staphylococcus aureus strain newman and comparative analysis of staphylococcal genomes: Polymorphism and evolution of two major pathogenicity islands. J. Bacteriol. 2008, 190, 300-310. [CrossRef] [PubMed]

34. Vimberg, V.; Kuzma, M.; Stodůlková, E.; Novák, P.; Bednárová, L.; Šulc, M.; Gažák, R. Hydnocarpin-Type Flavonolignans: Semisynthesis and Inhibitory Effects on Staphylococcus aureus Biofilm Formation. J. Nat. Prod. 2015, 78, 2095-2103. [CrossRef] [PubMed] 